\title{
La transmisión de valores a través del lenguaje cinematográfico Beatriz Peña Acuña Dykinson, Madrid, 2014
}

Juan Enrique Gonzálvez ${ }^{1}$ : Universidad Complutense de Madrid. España. juanen2012@gmail.com

En el panorama del ensayo audiovisual aparece un texto que sorprende positivamente por varios aspectos: por su planteamiento crea una nueva senda en la investigación audiovisual, por la profusión documental sintetizada, por la densidad de ideas y sugerencias en prospectiva para la futura investigación audiovisual, por la síntesis de disciplinas, teorías y autores respecto la comunicación y el audiovisual y por el cuidado del castellano. Un libro que marca un hito en ensayística e investigación por atreverse a plantear la transmisión de valores a través de los elementos propios del lenguaje audiovisual agrupando autores y teorías con argumentos de disciplinas multidisciplinares como las teorías de la Comunicación, teorías de recepción y audiencia, teorías de estudios de cine, enfoques de la Psicología sobre la emoción, experiencias pedagógicas respecto al uso del cine, y otras interesantes deducciones.

El texto ha sido incluido en la colección Clásicos Dykinson capitaneada por Alfonso Silván Rodríguez como monográfico. Esta colección se caracteriza por la selección de autores con cierto prestigio, obras escogidas por un planteamiento con nivel intelectual y esmero en el cuidado estilo lingüístico.

El primer capítulo se caracteriza por la descripción del valor de la dignidad con una fundamentación en la obra filosófica de autores que marcaron un hito como Aristóteles, Pico della Mirandola hasta Marta Nussbaum. Los tres siguientes capítulos construyen la argumentación respecto a los tres puntos de referencia en el proceso de comunicación: el cineasta -estudiado teniendo en cuenta el estado de la autoría y la intencionalidad-, el medio cinematográfico -como medio en sí y los elementos propios que despliega como herramienta en manos de la dirección- y el

\footnotetext{
${ }^{1}$ Juan Enrique Gonzalvez Universidad Complutense de Madrid. España. juanen2012@gmail.com
} 
espectador- desde los estudios de recepción, las emociones y el fenómeno de la identificación desde los estudios de cine y los de recepción.

Síntesis de currículo profesional del autor/es del libro reseñado:

\section{Nombre y apellidos completos del autor $1^{\circ}$ : Beatriz Peña Acuña}

Profesora titular de la Universidad Católica San Antonio (Murcia). Licenciada en Filología Hispánica y Periodismo. Diplomada en Estudios Humanísticos. Premio extraordinario de doctorado por la Universidad de Alicante (2012) por una tesis acerca del cineasta Steven Spielberg. Investigador principal del grupo internacional Desarrollo personal. Imparte docencia de Grados y Máster de Educación, Grado de Administración y Dirección de Empresas y Máster, y Posgrado en inglés. Profesora honoraria de Costa Rica. Su producción científica sobre Comunicación e investigación educativa es prolífica. 